\title{
Euclides da Cunha e a psicopatologia: um indício para abdução
}

Gisálio Cerqueira Filho

Este ensaio é um exercício de metodologia indiciária (Carlos Ginzburg), no qual a abdução tem papel relevante. $O$ foco é Euclides da Cunha, um dos mais famosos intelectuais brasileiros, autor de Os sertões, 1902. No campo da psicopatologia fundamental, destaca-se a obsessão de Euclides pela autonomia individual e uma certa dificuldade para mapear seus desejos.

Palavras-chave: Euclides da Cunha, obsessão, abdução, metodologia 
Para Roberto Ventura,

in memorian

para os alunos

que acompanharam o curso sobre Euclides da Cunha no Programa de Doutorado em Ciência Política (UFF) em 2006.2

Antes de tudo, algumas idéias aqui apresentadas podem parecer estranhas ou padecer de um certo exagero; por isso, solicitamos a indulgência e a benevolência do leitor.

Na lógica de Aristóteles a abdução é uma modalidade de silogismo em que a premissa maior é correta, e a menor, apenas provável, o que comprometeria a verdade irrefutável [ou não?] ${ }^{1}$ de uma conclusão que, todavia, se mantém logicamente necessária.

Para Charles Sanders Peirce ${ }^{2}$ trata-se de um primeiro momento de um processo de inferência, em que se busca formular uma hipótese mais geral que permita a explicação de determinados fatos empíricos. ${ }^{1}$ Carlo Ginzburg ${ }^{2}$ tem feito referência constante à abdução na sua metodologia indiciária e Sigmund Freud usou largamente nas suas interpretações de base psicanalítica.

Já no que concerne à psicopatologia fundamental, muitos autores, inclusive Roberto Ventura - do campo da crítica literária - têm tratado nestes termos a projeção especular de Euclides em Antonio Conselheiro, uma vez que ambos teriam sido traídos por suas respectivas mulheres e, a partir daí, assumido seus trágicos destinos: o sertão vale, pois, como uma metáfora eloqüente.

Mas neste artigo nosso interesse maior é na aparente "obsessão" de Euclides da Cunha pela insubmissão, autonomia e independência absolutas, contra toda forma de submissão às relações de dependência ou favor ("ideologia do favor").

1. Ver do autor, em co-autoria com Gizlene Neder, Emoção e política (especialmente p. 59/71, para um exercício abdutivo).

2. Numa interessante reflexão Carlo Ginzburg relaciona a metodologia indiciária tanto à abdução quanto à prova. Ver Relações de força: história, retórica, prova. 
A psicologia fundamental como disciplina científica é recente. O marco oficial data de 1913, com a publicação da obra Psicopatologia Geral, de Karl Jaspers, e a distinção da psiquiatria clínica como tal. O psicanalista francês Pierre Fédida redimensionou a psicopatologia denominando-a "psicopatologia fundamental" e referindo-se a uma encruzilhada epistemológica entre saberes heterogêneos que têm em comum a preocupação com o pathos. Tal concepção está presente na tragédia grega e anuncia que o pathos é o sofrimento (paixão também) constitutivo do humano enquanto tal (cf. Berlinck, 2000).

Todos sabemos que a formação de engenheiro militar comprometeu definitivamente Euclides da Cunha com a formação positivista de um Benjamim Constant e com o esprit de géometrie do paradigma iluminista. Todavia, a obra-prima literária - Os sertões - converte o que deveria ser uma simples reportagem para $O$ Estado de $S$. Paulo sobre a guerra de Canudos, numa inscrição também naquilo que Wittgenstein chama de esprit de finesse. Nesse ponto, seu movimento trágico inscrito numa moldura clássica, como chega a sugerir Berthold Zigly (1977) e a expressividade das metáforas e metonímias para dar conta de uma tragédia sangrenta que clama aos céus, acabam por conferir à magna obra efeitos estéticos muito além do paradigma hegemônico. Evidentemente, menos pela presença do humor e muito mais pela sensibilidade capaz de capturar elementos duros que envolvem a aridez da pobreza, da natureza, da religião popular comovente, que solda a solidariedade e se cristaliza na resistência política muito mais caricata do que inglória ou ineficaz, apesar de alguns rechaços diante de força militar muito superior em armas e gente.

Euclides da Cunha consegue chamar a si um estilo literário calcado tanto no esprit de géometrie quanto no esprit de finesse que ultrapassa a época histórica e serviu-lhe como passaporte para a entrada gloriosa na Academia Brasileira de Letras, fundada por Machado de Assis.

Euclides da Cunha foi um técnico muito importante do Ministério das Relações Exteriores, o Itaramaty. De fato, pertenceu ao núcleo de intelectuais que participou do Ministério no período de 1902 a 1912.

Pela importância adquirida com Os sertões, foi convidado pelo Barão do Rio Branco para desempenhar funções na expedição de reconhecimento do Alto-Purús (Acre), em 1905, trabalho que surgira como desdobramento das negociações do Tratado de Petrópolis.

Todos sabemos que Euclides da Cunha teve intensa participação na fixação das fronteiras do Brasil, seja produzindo relatórios para o Itamaraty, a pedido do Barão do Rio Branco, seja literalmente mapeando as áreas conflitivas. Um autêntico e detalhado mapa, produzido por Euclides, foi ajuntado, por exemplo, como documento imprescindível à Exposição de Motivos com que Rio Branco apresen- 
tou ao Presidente da República o tratado de 8 de setembro de 1909 com o Peru, nas regiões da bacia amazônica. Em relação ao Uruguai, outro exemplo, Afonso Pena anunciou oficialmente o novo projeto de fronteira em 2 de outubro de 1909 e o jornalista Manoel Bernardez (1913), assim narra como recebeu a notícia desta comunicação por intermédio do próprio Rio Branco que, na ocasião, estudava com Euclides da Cunha os novos limites fronteiriços ao sul do Brasil:

Convidei-o a entrar para lhe dar uma notícia de primeira mão. O senhor é o primeiro a ver este mapa das nossas fronteiras com o seu país, como desejamos que fiquem estabelecidas. Há muitos dias trabalho nisso e agora acabo de determinar com Euclides da Cunha a linha definitiva que correrá, como o senhor vê, ao longo do thalweg, eqüidistante das duas margens. Estou tomando, no momento, algumas notas para o estudo do tratado que devo levar ao presidente. (p. 48)

Euclides da Cunha esteve assim envolvido com funcionários do ministério, intelectuais e diplomatas com quem já mantinha relações de amizade, em particular depois que entrara para a Academia Brasileira de Letras, em 1904, inclusive o Barão. Podemos citar, entre os membros do corpo diplomático, Oliveira Lima, Domício da Gama, Gastão Cunha. Com eles, manteve longa correspondência escrita.

Assim, e sempre a convite deste último, esteve em missão, em várias oportunidades, em regiões inóspitas e longínquas do país. Não há dúvida que isso lhe trazia algum desassossego, pois deixava a família no Rio de Janeiro e acabava por ter pouco tempo para ela.

Mas o que queremos aqui provisoriamente ressaltar é que Euclides e Rio Branco privavam de larga convivência; muitos chegavam a dizer que Euclides pertencia à "igrejinha" do Barão, que acabava por proteger e apadrinhá-lo em sucessivas ocasiões. A própria admissão de Euclides na Academia Brasileira de Letras contara com o apoio forte do Barão. Há uma fotografia feita por Malta numa das varandas do palácio do Itamaraty, no Rio de Janeiro, em que lá estão os futuros da "turma do Barão". Todos homens; temos 12, em torno de Rio Branco, em visível destaque; mais parecem apóstolos...; estão sentados, ladeando Rio Branco à esquerda, Afonso Arinos e Barão Homem de Mello; à direita, Gastão da Cunha. Em pé, da esquerda para a direita estão Euclides da Cunha, Araújo Jorge, Graça Aranha, Eduardo Vergueiro, Lorena, César Vergueiro, Pecegueiro do Amaral, Cásper Líbero e Paulo Quartin.

O Barão do Rio Branco era um personagem invulgar; personalidade forte teve grande atuação na diplomacia brasileira, tanto na fixação das fronteiras com países vizinhos quanto nas relações internacionais e mesmo na projeção do Brasil no exterior (cf. Freyre, 1981, p. 220-53). Era um grande contador de casos, dotado de grande esprit de finesse; era um verdadeiro causer; além de jornalista e versado em arte, em geral, e literatura, em particular. Tinha gosto pela cultura, 
escrevia, sem assinar (às vezes com pseudônimo), tópicos para a imprensa; assinava matérias e editoriais para o Jornal do Comércio, O País, A Notícia. Utilizava-se de diversos pseudônimos: Nemo, Kent, J. Penn, Bernardo de Faria e Brasilicus. E alguns diziam que jogava bem capoeira... Ainda freqüentava com prazer cafés, restaurantes, locais da boemia carioca. Tinha grande afinidade com escritores e artistas. Tinha mesmo um especial domínio dos salões e era apreciado por sua extrema gentileza, particularmente em relação às mulheres. Cultivava a etiqueta e era dotado de grande sensibilidade.

O mesmo ano da chegada de Rio Branco ao Brasil (1902) coincide com o ano da publicação de Os sertões e Canaã, de Graça Aranha, como que a demonstrar a ligação subterrânea entre a diplomacia e as letras, numa época em que na literatura tínhamos os marcantes José de Alencar, Machado de Assis, Joaquim Nabuco, o próprio Euclides, para citar apenas alguns.

"Ser diplomata pelas mãos do Barão representava uma ambição [um desejo] para os escritores no início do século" (Lins, 1995, p. 409). Euclides tinha então 36 anos. É razoável que tivesse o desejo de ser diplomata.

O Barão do Rio Branco, por sua vez, era um vencedor. Consta que por volta de 1910 - é Álvaro Lins quem dá o depoimento - quando da visita da artista Sara Bernhardt ao Rio de Janeiro, este visitou-a no camarim, após o espetáculo, e ouviu da cantora, então no auge da fama e da glória: "c'est si bon de vaincre; vous le savez mieux que personne, Monsieur le Baron!” (p. 406 e 407).

Dele, assim falou Catalina Frias, esportista argentina que viera ao Rio de Janeiro com a delegação portenha para uma competição, e voltara para Buenos Aires encantada com Rio Branco:

Sei que ele é tão grande político como homem do mundo. Posso dizer que todos nós viemos presos pelo talento, a cortesia, o "esprit" desse ilustre brasileiro a quem se olha como uma glória viva. Não se pode conceber mais amabilidade sem afetação, mais lhaneza de trato dentro das fórmulas. ${ }^{3}$

Por certo que Euclides da Cunha o idealizava, num sentido rigorosamente psicanalítico.

Felizmente continuo a olhar para o Ministro a quem tenho servido - o único grande homem vivo desta terra - com a mesma admiração e simpatia. E até com assombro: é lúcido, é gentil, é trabalhador e traça na universal chateza destes dias uma linha superior e firme de estadista. (Lins, 1995, p. 406)

3. Entrevista da esportista Catalina Frias a El Diario, de Buenos Ayres e citado em Álvaro Lins, 1995, p. 305. 
Em sentido inverso, podemos, talvez, especular que grau de influência Euclides teria tido no grupo de intelectuais, políticos e diplomatas liderados pelo Barão do Rio Branco. Certamente os militares, e o exército, não acolhiam com tanta simpatia as páginas cáusticas e mais ferinas de Os sertões. Talvez julgassem Euclides com simplismo ou viés condenatório, até mesmo algum ressentimento, para quem, republicano de primeira hora, logo se desencantara com os militares e a ação genocida em Canudos. Entretanto, para o grupo do Barão, ele próprio incluído, e mesmo para o prestigiado Joaquim Nabuco, nosso embaixador nos Estados Unidos da América do Norte, Euclides desfrutaria de um julgamento muito mais complacente. Todos o aceitavam, naturalmente, sem que se perdesse a crítica.

Já para Euclides o Barão era admirável, motivo de contemplação, elevado à categoria de único grande homem da terra. Provocava-lhe assombro, desmaterializava-se num fantasma, numa fantasia, registro do imaginário de sombras; temor, medo, reverência, capaz de provocar-lhe assombração...

Em carta ao amigo Escobar, de São José do Rio Pardo, chegara a dizer pensando na hipótese impensável de substituição de Rio Branco, à frente do Itamaraty: "Ninguém poderá substituí-lo. Conheço pela metade as questões que nos ocupam no extremo norte, mas esta meia-noção basta-me a garantir-te que a substituição de Rio Branco, por quem quer que seja, será uma calamidade" (Venâncio Filho, 1938, p. 174-5).

Ou seja, para Euclides, na mais completa idealização do Barão, este era insubstituível.

Para posto de grande relevo na primeira embaixada do Brasil republicano escolheu Joaquim Nabuco, monarquista (que em carta prometeu seguir-lhe como um jesuíta ao seu Geral... perinde ac cadaver), ${ }^{4}$ para a representação do Brasil em Haia (Holanda) escolheu Rui Barbosa, para serviços técnicos do Ministério das Relações Exteriores, escolheu Euclides da Cunha. Segundo Álvaro Lins (1995):

... o Barão do Rio Branco ofereceu a Euclides o que ele mais desejava: o trabalho técnico, a aventura de pioneiro pelo interior do Brasil, a oportunidade de conhecer a terra e estudar suas fronteiras extremas. Depois de chefiar a missão de reconhecimento do alto Purus, permaneceria Euclides em serviços técnicos no Itamarati até a nomeação para o Colégio Pedro II. (p. 403)

Bem, ousamos o princípio da dúvida quanto ao desejo imputado ao outro como seu, quando não enunciado por ele mesmo no seu exclusivismo desejante.

4. Carta de Joaquim Nabuco ao Barão do Rio Branco, Arquivo do Itamarati; citado em Álvaro Lins, 1995, p. 401. Perinde ac cadaver (obediente como um cadáver) é o lema da Companhia de Jesus proposto por Inácio de Loyola. 
Não estamos convencidos quanto ao real do desejo de Euclides como um técnico do Itamaraty. Não gostaria, não desejaria ele uma função diplomática de maior reconhecimento e projeção internacional? Como Rui, como Nabuco? Vale o caráter dubitativo da reflexão. Recorde-se que, talvez, em razão do par amoroso que formava com Amélia com quem circulava abraçado no Rio de Janeiro, Clóvis Bevilacqua declinara do convite para viajar à Holanda (cf. Neder, 2002). Mas Euclides nunca fora convidado para um posto de maior destaque e, sobretudo, no exterior.

Já no passado, seis anos antes da publicação de Os sertões, o escritor Aluízio de Azevedo tornara-se diplomata, vice-consul em Vigo, na Galícia, e abandonara a literatura. Isso sem falar que Aluízio Azevedo aspirara um dia retratar a sociedade brasileira tal qual Émile Zola, na sua série naturalista Les RougontMacquart.

Ora, Euclides sempre encarara a vida como uma missão, senão no sentido evangélico e missionário da expressão, na acepção militar que ela encerra. Suas idas e vindas ao Brasil profundo eram marcadas pela descrição do sofrimento, do sacrifício, da renúncia.

A própria natureza da descrição hiperbólica da Amazônia, para Euclides, não inclui exatamente o princípio do prazer, no sentido freudiano, ou ainda o registro de gozo (jouissance) como a ele se refere Jacques Lacan. Antes, muito ao contrário a descrição se apóia na representação do inóspito, do desértico, do extraterrestre:

... há alguma coisa extraterrestre naquela natureza anfíbia, misto de águas e de terras, que se oculta, completamente nivelada, na sua própria grandeza. E sentese bem que ela permaneceria para sempre impenetrável se não se desentranhasse em preciosos produtos adquiridos de pronto sem a constância e a continuidade das culturas. As gentes que as povoam talham-se-lhes pela braveza. Não cultivam amorfoseando-a: domam-na. O cearense, o paraibano, os sertanejos nortistas em geral, ali estacionam, cumprindo, sem o saberem, uma das maiores empresas destes tempos. Estão amansando o deserto. E as suas almas simples, a um tempo ingênuas e heróicas, disciplinadas pelos reveses garantem-lhes, mais que os organismos robustos, o triunfo na campanha formidável. (Cunha, 1909, p. 49)

Álvaro Lins (1995) vai adiante e produz fragmento de lembrança que ganha cores de tragicômico, mais parece um sonho sonhado:

Conta-se que ele (Euclides) e Rio Branco ficavam às vezes a discutir, madrugada adentro, assuntos de história ou problemas brasileiros. Em algumas noites, Euclides, já deitado, como hóspede da Casa Westphalia, entrava-lhe pelo quarto o Barão, vindo de alguma festa ou solenidade, e ficavam os dois a conversar, um de casaca e cartola, o outro debaixo dos lençóis - numa intimidade de intelectuais que não excluía o cerimonioso tratamento pessoal: 


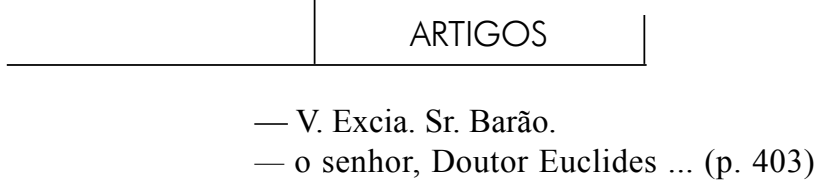

Seria trágico, se não fosse cômico; e acabou por ser trágico... 5

Euclides, ainda aqui o benefício da dúvida, tinha horror ao favor; seria incapaz de pedir qualquer coisa ao Barão (um posto no exterior?) ainda que este tivesse tantos privilégios que se dizia ao corrente no Foro "para o Barão, nem selo", "isentando-o de qualquer espécie de pagamento em qualquer circunstância" (Otávio, 1935 , p. 178 e 180 ).

De todo modo, após entrar para a Academia Brasileira de Letras (ABL) e, glória suprema, para o Instituto Histórico e Geográfico Brasileiro (IHGB), Euclides da Cunha optara por fazer o concurso para a cátedra de Lógica do Ginásio Nacional, assim se chamava com viés republicano, o Colégio Pedro II. Concorreu com Farias Brito e ficou em segundo lugar na classificação. Entretanto, foi nomeado em detrimento do primeiro colocado. Iniciou o curso no meio do ano, dizendo-se obrigado “... a sapecar matéria para preencher o programa... levo-o numa grande convicção pedagógica. Ao menos, direi aos meus alunos a simples e límpida lógica de Stuart Mill, ao invés de transcendentais tolices metafísicas". ${ }^{6}$

Não deixa de ser interessante recordar que Sigmund Freud, quando era estudante, traduzira para o alemão o ensaio "A sujeição das mulheres", de Stuart Mill para a edição das obras reunidas de Mill que estava sendo organizada por Theodor Gomperz. Este era colega de Von Hartel (então Ministro da Cultura em Viena). Freud não tivera constrangimento de pedir a Elise Gomperz, esposa de Theodor Gomperz, e sua paciente há 15 anos, para interferir junto ao ministério na sua nomeação, que não saía, para docente da Universidade (medicina) e que ele desconfiava estar travada por preconceito, no caso, antijudaico. Theodor não se envolvera com o pedido, mas Elise tentara e, todavia, não conseguira nada com o Ministro. Ressalte-se, todavia, que Freud trabalhara arduamente na interpretação do porquê sua nomeação não saía e ele tinha tanta dificuldade em pedir por ela a alguém. Só quando desconectou o pedido do par autonomia/submissão do sujeito, ousou assumir e sustentar o seu desejo; pedir por ele. Ainda assim, acabou por só conseguir a nomeação recorrendo posteriormente à baronesa Marie Ferstel, esposa do diplomata Heinrich Ferstel, o arquiteto que construíra a nova

5. Para a composição dramática que não faltam os componentes da tragédia e da comédia ver especialmente Slavoj Zizek, The Fragil Absolut, em particular o capítulo "From tragique to moque-comic".

6. Ante-penúltima carta de Euclides da Cunha, datada de 8 de agosto de 1909, e endereçada a seu cunhado Otaviano da Costa Vieira, advogado e magistrado no interior paulista, em Nogueira Galvão, 1997.

Rev. Latinoam. Psicopat. Fund., São Paulo, v. 11, n. 3, p. 380-391, setembro 2008 
universidade. A baronesa, também analisanda de Freud, agiu rápido, entrou em contato com Hartel, fez o pedido e prometeu em troca uma pintura de Arnold Bocklin para a "Galeria Moderna" que logo seria inaugurada e era a paixão de Hartel. O processo andou, percorreu sem problemas o trâmite burocrático e a pintura foi entregue, mas não exatamente um Bocklin, pioneiro da modernidade e que ela não conseguira, mas uma outra pintura, de Emil Orlick, um dos pintores secessionistas mais conservadores. Num dia de março de 1902 a nomeação de Freud foi publicada (cf. Schorske, 1961, p. 235).

A nomeação de Euclides para o magistério foi publicada em meados de 1909. Um mês após a nomeação morria assassinado em 15 de agosto de 1909, ao tentar alvejar Dilermando de Assis, cadete militar, campeão de tiro e amante de Ana Solon Ribeiro da Cunha (Saninha). Mais tarde Saninha casar-se-ia com Dilermando.

Por seu turno, Farias Brito, que era professor de Filosofia Jurídica na Faculdade de Direito do Pará, transferira-se para o Rio de Janeiro a fim também de concorrer à cátedra de Lógica no mesmo Ginásio. Primeiro colocado, embora preterido, acabou por assumi-la, sem novo concurso, graças a um parecer de Silvio Romero, aprovado pela congregação do educandário. Então já era autor de obra de caráter eminentemente moral e de acentuado tom trágico. Acabou por constituir-se num dos maiores ideólogos do protofascismo brasileiro, denominado integralismo por seu líder máximo (füehrer) Plínio Salgado.

À parte os embates, atravessados por picuinhas de natureza acadêmica da "República das Letras", que se travaram entre Farias Brito e Euclides da Cunha e, sem prejuízo da busca da verdade histórica, que no dizer de Jacques Lacan estruturar-se-á como ficção, gostaríamos de assinalar como se inscreve neste episódio o Barão do Rio Branco, chefe funcional no Itamaraty, de Euclides da Cunha. Euclides o serviu com reserva sim, mas também com idealismo e idealização, pagando com a vida um desejo (ir para o exterior como diplomata?) que não soube ou não pôde sustentar; preferindo ausentar-se de casa, mulher e filhos, embrenhando-se pelo Brasil geograficamente desértico, nas suas próprias palavras, mas que afinal acaba por produzir um deserto na alma e no coração, que se amalgamava ao real do desejo subitamente surpreendido por uma bala tragicamente assassina.

Recorda-nos o Barão: ${ }^{7}$

Decide-se agora a escolha do lente de Lógica para o Ginásio Nacional. Não dei até um passo em favor de Euclides da Cunha por entender que ele não precisa disso. Agora, porém, que sei ter havido uma escandalosa cabala contra ele no seio da congregação e que outros candidatos recorrem a padrinhos ou pistolões,

7. Carta a Francisco da Veiga datada de 12 de março de 1909, Arquivo do Itamarati. 
como diz o povo; sinto-me obrigado - sem pedido algum dele - a queimar cartucho em favor desse moço puro e digno que é uma inteligência de primor.

Na carta do Barão tudo está resumido: contra a cabala, o pistolão... queimar cartucho, mobilizar recursos e força política, enfim, o favor em prol do moço que estivera sempre ao seu lado e leal, no Itamaraty, agora já um patrício ilustre. $\mathrm{O}$ favor poderia ter vindo sem a conotação de pistolão ou privilégio, mas embrulhado na mais genuína solidariedade, na mais autêntica dádiva de camaradagem, como falava Mário de Andrade. Mas para isso, antes de tudo, era necessário que o desejo de Euclides de ser algo mais que um funcionário técnico no Itamaraty fosse plenamente assumido e sustentado perante o amigo Barão. Isso não fora feito a tempo e a hora. Quando queimou-se o cartucho já era tarde.

E ao "pistolão", como diz o povo, acabou por impor-se o eco de cada estampido terrível, seco, de um revólver Smith and Wesson calibre 22 contra os de uma pistola calibre 38 nas mãos de um exímio atirador; enfim, Euclides estava morto, abatido diante da escada da chamada casa da Piedade, episódio logo reconhecido como a "tragédia da Piedade". Assassinato? Há controvérsia..., ainda hoje. Ao chegar na casa onde se encontravam Saninha, os filhos, Dilermando, dizendo "vim disposto a matar ou morrer", há quem suspeite de suicídio vestido de homicídio ou vice-versa. O fato é que, defendido por Evaristo de Moraes, Dilermando foi absolvido.

Lázaro Curvello Chaves, que foi diretor da Casa de Cultura Euclides da Cunha, em São José do Rio Pardo, diz $^{8}$ que "há estudos ainda hoje para averiguar se de fato não ocorrera um suicídio. Mal de saúde, talvez tuberculoso, com vários tumores no corpo, coração avariado, partiu para um desafio desproporcional. Uma pistola 22" contra um revólver 38 " nas mãos de um exímio atirador..."

\section{Referências}

BerLinck, M. Psicopatologia fundamental. São Paulo: Escuta, 2000.

Bernárdez, M. Rio Branco y el Uruguay. Revista Americana, p. 48, abril de 1913.

Cerqueira Filho, G. e Neder, G. Emoção e política. Porto Alegre: Sergio Fabris Editor, 1997.

CunHA, E. da (1902). Os sertões. São Paulo: Ática, 2000.

8. Declaração do Prof. Lázaro Curvelo Chaves ao autor em 19/12/2006. 
1913.

(1909). Um clima caluniado. In: À margem da história. Porto: Livraria Chardron

Freyre, G. Rio Branco: a estátua e o homem. In: Freire, G. Pessoas, coisas \& animais: ensaios, conferências e artigos reunidos e apresentados por Edson Neri da Fonseca. Rio de Janeiro: Globo, 1981. (Publicado originalmente no Diário de Pernambuco, Recife, 10, 12-6, 19 mar.1946)

Ginzburg, C. Relações de força: história, retórica, prova. São Paulo: Companhia das Letras, 2002.

LeE, A. O sorriso da sociedade. Rio de Janeiro: Objetiva, 2006.

Lins, A. Rio Branco (biografia). Fundação Alexandre de Gusmão. São Paulo: AlfaÔmega, 1995. p. 409.

Neder, G. Amélia e Clóvis Bevilacqua: o casamento, o casal e a idéia de indivíduo. Anais, X Encontro Regional de História da ANPUH, UERJ, Rio de Janeiro, 14 a 18 de outubro de 2002.

Nogueira Galvão, W. Correspondência de Euclides da Cunha. São Paulo: Edusp, 1997.

Octavio, R. Minhas memórias dos outros. Rio de Janeiro: José Olympio, 1935.

Schorske, C. (1961). Viena fin de siècle: política e cultura. São Paulo: Companhia das Letras, 1989.

Silva, D.A.D. da. Apontamentos introdutórios para sua dissertação de mestrado "Ubiquae Patriae Memor: o Círculo Rio Branco, alteridade e idéia de nação no Brasil na passagem à modernidade", orientação da Profa. Dra. Gizlene Neder, Programa de PósGraduação em História da Universidade Federal Fluminense (ICHF-UFF), Niterói, 2006, mimeo.

VenÂncio Filho, F. Euclides da Cunha a seus amigos. São Paulo: Companhia Editora Nacional, 1938. (Brasiliana).

Villa, M.A. Canudos: o povo da terra. São Paulo: Ática, 1995.

ZILly, B. (1977). War as a picture and a spetacle. History staged in Os Sertões. Conferência na semana euclidiana de 1997, São José do Rio Pardo, SP, 1977, mimeo.

ZIzeK, S. The Fragil Absolut. London/New York: Verso, 2002.

\section{Resumos}

(Euclides da Cunha y la psicopatología: un indicio para abducción)

Este trabajo es un ejercicio de metodología indiciaria (Carlos Ginzburg) en el cual la abducción tiene un papel relevante. El foco es Euclides da Cunha, uno de los 
más prestigiados intelectuales brasileños, autor de Os sertões, 1902. En el campo de la psicopatología fundamental, se destaca la obsesión de Euclides por la autonomía individual y una cierta dificultad para mapear sus deseos.

Palavras claves: Euclides da Cunha, obsesión, abducción, metodología

(Euclides da Cunha et la psychopathologie: un indice d'abduction)

Ce travail est un exercice de méthode indiciaire (Carlos Ginzburg), dans lequel l'abduction joue un rôle central. Il porte sur Euclides da Cunha, important intellectuel brésilien, qui a écrit Os sertões, en 1902. Dans le champ de la psychopathologie fondamental, la discussion porte sur l'obsession d'Euclides pour l'autonomie individuelle et sur une certaine difficulté de cartographier ses désirs.

Mots clés: Euclides da Cunha, obsession, abduction, méthode

(Euclides da Cunha and psychopathology: indications of abductive reasoning)

This essay is an exercise on the methodology of the indiciary paradigm (Carlos Ginzburg), where evidence and abductive reasoning are essential. The main subject of discussion is Euclides da Cunha, one of Brazil's most famous intellectuals and author of Rebellion in the Backlands (1902). In the field of fundamental psychopathology, the specifc theme here is Da Cunha's obsession with individual autonomy and a certain difficulty in mapping his own desires.

Key words: Euclides da Cunha, obsession, abductive reasoning, methodology

Versão inicial recebida em janeiro de 2007 Versão aprovada para publicação em junho de 2008

\section{Gisálio Cerqueira Filho}

Doutor em Ciência Política; professor Titular de Sociologia e Associado II de Teoria Política; docente e pesquisador senior na Universidade Federal Fluminense (Niterói, RJ, Brasil), atua nos Laboratórios de Psicopatologia Fundamental, Psicanálise e Psicossomática (LP3F) e Cidade e Poder (LCP).

Rua Bom Pastor, 107/901 - bloco 1 - Tijuca

20251-060 Rio de Janeiro, RJ

Fone: (21) 2254-6936

e-mail: gisalio@superig.com.br 